\title{
KESAKSIAN VIVIAN BULLWINKLE SEBAGAI KORBAN KEKEJAMAN JEPANG DI PULAU BANGKA PADA TAHUN 1942 SEBAGAI SUMBER PEMBELAJARAN SEJARAH
}

\author{
Oleh: Meri Safitri*, Ida Suryani** \\ * Mahasiswa Program Studi Pendidikan Sejarah Universitas PGRI Palembang \\ ** Dosen Program Studi Pendidikan Sejarah Universitas PGRI Palembang
}

\begin{abstract}
ABSTRAK
Adapun rumusan masalah dalam penelitian ini adalah: Bagaimana sejarah kesaksian Vivian Bullwinkle sebagai korban kekejaman Jepang di pulau Bangka pada tahun 1942 dapat dijadikan sebagai sumber pembelajaran sejarah?. Sedangkan tujuan dari penelitian ini yaitu: (a) Untuk mengetahui kesaksian Vivian Bullwinkle sebagai korban kekejaman Jepang di pulau Bangka pada tahun 1942.(b) Untuk mengungkapkan gambaran kehidupan di pulau Bangka pada masa penjajahan Jepang melalui kesaksian suster Vivian Bullwinkle. (c) Untuk mengetahui kesaksian Vivian Bullwinkle sebagai korban kekejaman Jepang di pulau Bangka pada tahun 1942 dapat dijadikan sebagai sumber pembelajaran sejarah. Metode yang digunakan dalam penelitian ini adalah metode deskriptif kualitatif dengan teknik pengumpulan data melalui observasi, wawancara, dan dokumentasi. Sedangkan teknik analisis data yang digunakan dalam penelitian ini adalah teknik analisis data analisis interaktif melalui pengumpulan data, reduksi data, display data, dan verifikasi atau penarikan kesimpulan. Dari hasil penelitian ini dapat disimpulkan bahwa: kesaksian Vivian Bullwinkle sebagai korban kekejaman Jepang di Pulau Bangka pada tahun 1942 dapat dijadikan sumber pembelajaran sejarah. Kesaksian Vivian Bullwinkle memberikan keterangan lebih detail mengenai penjajahan Jepang di pulau Bangka, mengungkap cerita dari bangkai kapal yang kini terdampar di garis pantai Tanjung Kalian, hingga terjadinya penembakan massal di kawasan tersebut pada tahun 1942 dan disampaikan pada siswa dengan menggunakan strategi CTL (Contextual Teaching and Learning) agar siswa dapat lebih mudah memahami materi Zaman Penjajahan Jepang di Indonesia dengan memanfaatkan sejarah lokal.
\end{abstract}

Kata Kunci: Kesaksian Vivian Bullwinkle, Korban Kekejaman Jepang di Pulau Bangka tahun 1942, Sumber Pembelajaran Sejarah

\section{A. PENDAHULUAN}

Di dalam usahanya untuk membangun suatu imperium di Asia, Jepang telah meletuskan suatu perang di Pasifik. Pada tanggal 8 Desember 1941 secara tiba-tiba Jepang menyerbu ke Asia Tenggara dan membom Pearl Harbour yakni pangkalan terbesar Angkatan Laut Amerika di Pasifik. Lima jam setelah penyerangan atas Pearl Harbour itu, Gubernur Jenderal Hindia Belanda Tjarda van Starkenborgh Stachouwer menyatakan perang terhadap Jepang (Poesponegoro, 1993:01).

Masa pendudukan Jepang selama tiga setengah tahun merupakan salah satu periode yang paling menentukan dalam sejarah Indonesia. Sebelum serbuan Jepang tidak ada satupun tantangan serius terhadap kekuasaan Belanda di Indonesia (Ricklefs, 2011:297). Jepang memulai serangan ke Hindia Belanda pada tanggal 11 Januari 1942 dengan menaklukkan tarakan, Kalimantan Timur. Serangan kemudian dilanjutkan ke Balikpapan yang merupakan sumber minyak kedua di Indonesia dan berhasil ditaklukkan oleh tentara Jepang. Jepang menyerang Palembang pada tanggal 14 Februari 1942 dengan mendaratkan pasukan payung di Palembang dan berhasil diduduki dua hari kemudian. Jepang juga berhasil menduduki Bangka Belitung sebagai pusat penghasil timah dan lada dari tangan pemerintah Hindia Belanda (Poesponegoro,1993:3-4) . Jepang mulai menguasai Asia Tenggara pada tahun 1942. Setelah menduduki Palembang pada tanggal 14 
Februari 1942 jepang kemudian menguasai Singapura pada 15 Februari 1942. Dua hari kemudian Jepang menduduki Bangka. Heidhues (2008) mencatat, Jepang mengambil alih pertambangan Timah di Bangka, Belitung, dan Singkep, lalu menyerahkannya kepada Mitsubishi untuk mengelolanya (Theo, 2014:27). Pulau Bangka mengalami masa-masa yang suram sejak masa pendudukan Jepang, kuli-kuli timah sangat menderita karena mereka harus bekerja sepanjang hari tanpa makan dan pakaian yang layak. Bukti lain yang menunjukkan kekejaman Jepang selama memerintah di pulau Bangka adalah dengan terjadinya tragedi Vyner Brooke di selat Bangka pada tanggal 14 Februari 1942 ketika Jepang menaklukkan Palembang dan sekitarnya termasuk pulau Bangka.

Tragedi Vyner Brooke merupakan tragedi penembakan oleh tentara Jepang terhadap kapal milik Australia yang bertolak dari Singapura menuju Australia dengan membawa tentara dan juru rawat asal Australia pasca Jepang membom Singapura pada hari sebelumnya. HMS Vyner brooke di tembak oleh pasukan Jepang ketika melintasi selat Bangka. HMS Vyner Brooke membawa 65 orang maskapai beserta juru rawat asal Australia yang ditugaskan di Singapura sejak bulan September 1941 hingga akhirnya mereka dipulangkan pada bulan Februari 1942 setelah Jepang membom Singapura pada bulan yang sama.

Sumber mengenai pemerintahan jepang di pulau Bangka sangatlah kurang. . Kesaksian Vivian Bullwinkle ini memberikan gambaran lebih detail mengenai sepak terjang Jepang di Pulau Bangka selain dominasi Jepang pada timah dan lada di pulau tersebut. Hal inilah yang membuat penulis tertarik untuk melakukan penelitian dengan judul "Kesaksian Vivian Bullwinkle sebagai korban kekejaman Jepang di pulau Bangka pada tahun 1942 sebagai sumber pembelajaran sejarah".

\section{B. METODE PENELITIAN}

Berdasarkan rumusan masalah, penelitian ini mendeskripsikan secara rinci tentang sejarah kesaksian Vivian Bullwinkle sebagai korban kekejaman Jepang di pulau Bangka pada tahun 1942. Untuk memahami hal tersebut, dilakukan penelitian secara mendalam dengan menggunakan pendekatan deskriptif kualitatif. Sumber Data. Sumber data dalam penelitian ini adalah: Informan, Dokumen, Tempat penelitian di provinsi Bangka Belitung. Teknik Pengumpulan Data: Wawancara Mendalam, Kajian Dokumen, Observasi Langsung di desa Ulak Beriang.

Teknik Cuplikan. Peneliti dalam melakukan kegiatan penelitian ini menggunakan teknik cuplikan purposive sampling pada warga masyarakat yang menyimpan sastra tutur. Validitas Data. Validitas data sangat penting dalam proses pemaparan hasil penelitian, pembahasan dan penarikan simpulan. Dengan adanya validitas data triangulasi yang digunakan: triangulasi data, triangulasi metode.

\section{HASIL DAN PEMBAHASAN} Kesaksian Vivian Bullwinkle sebagai Korban Kekejaman Jepang

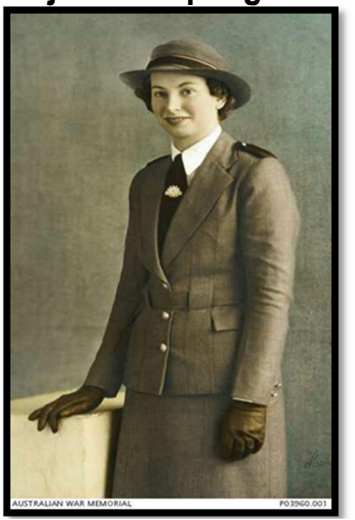

Keterangan: Potret Vivian Bullwinkle tahun 1941 Sumber: Dokumentasi Australian War Memorial

Vivian Bullwinkle lahir di Kapunda, sebuah wilayah di Australia selatan pada tanggal 18 Desember 1915. Ayahnya bernama George Francis dan ibunya bernama Eva Bullwinkle. la memiliki 
seorang saudara laki-laki bernama John. la memulai pelatihan sebagai seorang perawat dan bidan di rumah sakit Broken Hill, New South Wales kemudian melanjutkan karir keperawatannya di Hamilton, Victoria sebelum kemudian dipindahkan ke rumah sakit Jessie McPherson di Melbourne. Pada tahun 1941 ia pernah mendaftarkan diri sebagai seorang relawan di Royal Australian Air Force namun beliau tidak terpilih karena kurang dari standar penerimaan. Kemudian ia bergabung dengan pelayanan keperawatan tentara Australia dalam 2/13 Australian General Hospital (2/13 AGH) yaitu sebuah organisasi yang terbentuk di Melbourne's Caulfield Rececourse pada tanggal 11 Agustus 1941. Pada bulan September 1941 mereka berangkat untuk ditugaskan di Singapura. Ketika tiba di Singapura mereka bergabung dengan $13^{\text {th }}$ AGH di Johor Baharu. la hanya bertugas kurang dari enam bulan di Singapura sebelum dipulangkan kembali ke Australia bersama para rekan $13^{\text {th }} \mathrm{AGH}$ lainnya pasca Singapura diserang dan dikuasai oleh Jepang pada tanggal 15 Februari 1942. Rombongan mereka adalah kelompok juru rawat terkahir yang bertolak dari Singapura pada tanggal 13 Februari 1942 dan di bom oleh Jepang keesokan harinya. la merupakan satu-satunya korban selamat dari penembakan massal di pantai Radji pasca pemboman terhadap HMS Vyner Brooke di kawasan selat Bangka pada tanggal 14 Februari 1942.

Dalam sebuah jurnal dari Australian War Memorial oleh Hank Nelson di jelaskan bahwa Vivian Bullwinkle adalah satusatunya saksi hidup dari penembakan massal tersebut, seperti yang dikutip berikut.

Dalam paper beliau di Australian War Memorial, pasca perang beliau aktif sebagai ahli repatriasi di rumah sakit Hiedelberg. Kemudian pada tahun 1955 hingga 1970 ia aktif sebagai letnan kolonel di 3 Royal Australian Nursing Corps Training Unit. Beliau pensiun pada tahun 1977 dari rumah sakit Fairfield Infection Diseases, Victoria. Ketika bekerja di rumah sakit tersebut beliau terlibat dalam sebuah organisasi untuk misi evakuasi dan pengobatan anak yatim pada perang Vietnam di Saigon dan mengawasi pemulihan mereka sebelum di adopsi oleh keluarga Australia. Beliau juga aktif di organisasi pelang merah dan beberapa organisasi kemanusiaan lainnya.

Vivian Bukkwinkle menerima banyak medali dan penghargaan atas keberaniannya untuk memberikan kesaksian atas pembunuhan massal tersebut serta kehidupannya selama menjadi tawanan perang di pengadilan kriminal perang di Tokyo pada tahun 1947. Pada tahun 1992 ia bersama beberapa rekannya dan keluarga anggota $13^{\text {th }} \mathrm{AGH}$ kembali ke Muntok guna meresmikan sebuah monumen untuk mengenang para sahabat serta keluarga yang meninggal diselat Bangka, korban penembakan massal ataupun yang meninggal selama menjadi tawanan perang Jepang di pulau Bangka.

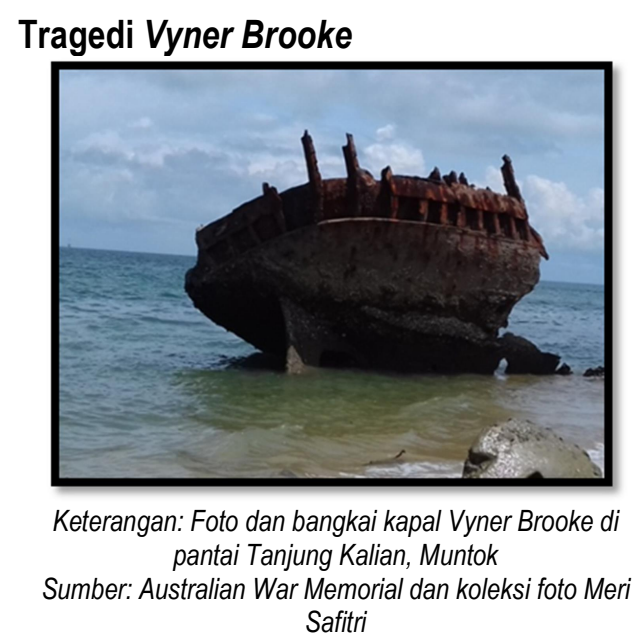

Pada tanggal 8 Desember 1941, Jepang membom pangkalan Armada Laut Amerika di Pearl Harbour, kepulauan Hawaii yang merupakan armada laut terbesar Amerika yang memicu terjadinya Perang dunia II di Asia Pasifik. Jepang kemudian melakukan penaklukkan berantai di beberapa daerah untuk mencari dukungan 
dari negara lain untuk membantunya dalam memenangkan Perang Asia Timur Raya. Jepang berhasil menguasai Singapura pada tanggal 15 Februari 1945. Pat Daling mengutip dalam bukunya "Potrait of a Nurse: Prisoner of war of the Japanese 1942-1945 Sumatra" mengenai keadaan Singapura ketika di serang oleh tentara Jepang sebagai berikut:

Jepang melakukan serangan umum ke Singapura pada tanggal 8 Februari 1942 dan Singapura jatuh dibawah komando Jepang pada tanggal 15 Februari 1942. Dalam proses penakulukkannya di Singapura, Jepang telah memiliki kurang lebih 130.000 tawanan dibawah komando tentara Inggris. Tentara Jepang menyerang pusat kota, membom tank penyimpanan miyak, hingga membom pelabuhan di Singapura. Setelah sebagian orang dievakuasi menggunakan kapal Empire Star, kemudian kapal Prince Wales, HMS Vyner Brooke merupakan kapal terakhir yang diberangkatkan dari Singapura pada tanggal 12 Februari 1942 dengan membawa 65 orang juru rawat asal Australia, para personil RAF (Royal Air Force) atau Angkatan Udara Britania Raya, para tentara, serta warga sipil yang kebanyakan adalah para wanita dan anak-anak. Vyner Brooke adalah sebuah kapal milik Inggris yang akan berlayar menuju Australia. Kapal ini bukanlah sebuah kapal bermuatan besar dan ketika diberangkatkan dari Singapura kapal ini sudah kelebihan muatan. Kapal ini berangkat dengan komando dari kapten Richard E. Tubby Borton.

Para pengintai yang ia maksud ialah para tentara Jepang yang sejak tanggal 13 Februari 1945, dua hari sebelum menguasai Singapura Jepang telah menguasai Palembang dan wilayah sekitarnya. Sejak penguasaan itu, Jepang menempatkan banyak pesawat pengintai termasuk di kawasan selat Bangka dan kapten Borton memutuskan untuk menyembunyikan Vyner Brooke di belakang pulau Linggo pada siang hari dan mulai berlayar ketika malam tiba.
Hal ini ia lakukan untuk menghindari pesawat pengintai Jepang yang terus berpatroli di siang hari.

Pulau Linggo adalah sebuah pulau kecil diantara banyak pulau yang berada di sekitar kepulauan Riau. Pulau ini dipilih sebagai tempat persembunyian karena dipulau ini terdapat sebuah bukit yang memugkinkan Vyner Brooke dapat disembunyikan dengan aman di belakang pulau ketika siang hari saat pesawatpesawat pengintai milik Jepang beroperasi di kawasan selat Bangka dan perairan sekitarnya. Setelah menaklukkan Sumatera Selatan pada tanggal 13 Februari 1942, pesawat-pesawat pengintai Jepang semakin semakin sering melakukan patroli dikawasan ini bahkan hingga 5 kali sehari.

Pada tanggal 14 Februari 1942 tepatnya pukul 11 a.m. mereka mendengar suara dari pesawat pengintai Jepang mendekat dengan ketinggian sekitar 2000 $\mathrm{km}$ dan melintas sangat cepat denagn membentuk formasi V. Pesawat-pesawat pengintai ini mulai meluncurkan beberapa bom dan gagal. Vyner Brooke adalah sebuah kapal dengan ukuran yang kecil dan kapten Borton adalah seorang kapten yang berpengalaman, ia membuat kapal melaju dengan jalur berliku-liku. Vyner Brooke dapat menghindari beberapa serangan Jepang. Kemudian pesawat pengintai Jepang kembali dan kembali melontarkan dua puluh tujuh bom dengan membentuk formasi melingkar mengelilingi Vyner Brooke dan salah satu bom mengenai bagian kanan cerobong kapal hingga merobohkannya.

Serangan dilanjutkan dan menimbulkan beberapa kerusakan fatal pada Vyner Brooke. Para penumpang mulai dievakuasi. Mereka diinstruksikan untuk mengenakan jaket keselamatan dan bersiap menaiki sekoci. Vyner Brooke hanya memiliki enam buah sekoci dan tiga diantaranya dalam kondisi berlubang sehingga tidak layak untuk digunakan. Penduduk sipil dan anak-anak serta mereka 
yang terluka harus dievakuasi naik sekoci terlebih dahulu dibantu beberapa tentara dan para perawat dan mereka yang bisa berenang harus berenang.

Penumpang lainnya harus berenang meninggalakan kapal termasuk suster Vivian Bullwinkle yang harus berenang menggunakan jaket keselamatan. Beberapa dari mereka terluka. Orang yang terakhir meninggalkan kapal adalah salah seorang rekan Vivian Bullwinkle yaitu Jessie Blanch. Vyner Brooke ditenggelamkan oleh pesawat pengintai Jepang dalam kurun waktu sekitar lima belas menit sejak Jepang melontarkan bom pertama.

Namun HMS Vyner Brooke bukanlah satu-satumya maskapai yang ditembak dan ditenggelamkan oleh tentara Jepang di kawasan selat Bangka ketika Jepang menjajah Indonesia, dalam satu minggu pada pertengahan bulan Februari 1942 saja Jepang telah menenggelamkan tujuh puluh kapal di kawasan selat Bangka.

Hal serupa juga dikemukakan oleh lan W. Shaw dalam bukunya yang berjudul On Radji Beach sebagai berikut: The Vyner Brooke was one of about 70 ships sunk in and around the enterence to Banka strait in a 48 hour period commercing at daylight on Friday, 13 February 1942 (Shaw, 2010: 164). Vyner Brooke adalah salah satu dari sekitar 70 kapal yang tenggelam di dan sekitar selat Bangka dalam kurun waktu 48 jam dimulai pada siang hari Jumat, 13 Februari 1942.

Berdasarkan uraian diatas dapat disimpulkan bahwa tragedi Vyner Brooke merupakan tragedi penembakan dan pemboman terhadap maskapai milik Australia Vyner Brooke yang membawa juru rawat asal Australia yang bertugas di Singapura sejak tahun 1941 beserta beberapa penduduk sipil serta tentara Inggris. Maskapai ini di tenggelamkan oleh tentara Jepang di perairan selat Bangka pada tanggal 12 Februari 1942 dan korban yang selamat segera berenang ataupun menaiki sekoci untuk mencapai daratan terdekat di wilayah kota Muntok tepatnya di kawasan pantai Radji.

\section{Penembakan Massal di Kawasan Pantai Tanjung Kalian}

Akhirnya hanya dua sekoci yang bisa digunakan untuk mengangkut penumpang dan sisanya berenang menuju daratan terdekat yaitu kawasan pantai Tanjung kalian tepatnya pantai Radji. Sekoci pertama tiba dengan membawa 20 orang penumpang yang terdiri dari warga sipil, beberapa perawat, empat orang awak kapal Vyner Brooke, dan beberapa orang lainnya. Ketika malam, sekoci lainnya mencapai pantai juga penumpang lainnya yang berenang hingga mencapai pantai. Tak lama berselang, tiba sekoci lain di pantai tersebut. Sekoci tersebut mengangkut lebih banyak penumpang dan mereka berasal dari kapal lain yang di tangkap dan ditenggelamkan oleh pesawat pengintai Jepang di kawasan selat Bangka.

Dalam kelompok terpisah lainnya, beberapa orang juru rawat dan korban selamat dari Price of Wales yang juga di bom Jepang, serta beberapa awak kapal Vyner Brooke ditemukan oleh tentara Jepang.

Jepang sangat ingin mengetahui keberadaan orang Amerika yang merupakan rival mereka dalam Perang Dunia II dari kapal-kapal yang telah mereka tenggelamkan di kawasan Malaya dalam kurun waktu tiga hari sejak tanggal 13 hingga 15 Februari 1942. Jepang terus berpatroli untuk mengamankan daerah yang telah mereka rebut sementara pasukan lainnya bergerak untuk melakukan invasiinvasi lain di wilayah Indonesia.

Sementara dalam kelompok besar di tepi pantai, prioritas mereka saat itu adalah keselamatan dari orang-orang yang terluka, dan seorang dokter asal Cina, Marton Drummond dan beberapa orang perawat yang bertanggungjawab atas orang-orang yang terluka. Semua orang kemudian dibagi kedalam dua kelompok dibawah komando 
Bill Sedgeman. la kemudian memerintahkan beberapa orang untuk menelusuri hutan didekat pantai agar menemukan jalan keluar dan mencari bahan makanan dan meminta lima suster untuk menjadi relawan dan ikut serta. Vivian Bullwinkle adalah salah satu dari relawan itu. Akhirnya, Sedgemen dan kelompok kecil itu meninggalkan pantai dan mulai memasuki hutan.

Ketika menelusuri hutan mereka menemukan sebuah kampung melayu. Mereka bertemu tiga orang pria tua dan Sedgemen mencoba menjelaskan tentang keadaan mereka menggunakan kombinasi bahasa tubuh agar pria-pria tersebut mengerti. Seorang pria kemudian menjelaskan dengan bahasa tubuh agar mereka menyerahkan diri kepada Jepang sebagai penyelesaiannya dan tentara jepang mungkin akan memberi mereka makan dan minum. Kelompok kecil itu kemudian kembali ke pantai setelah berterima kasih. Kondisi mereka semakin memburuk, banyak orang-orang yang butuh pertolongan medis, mereka kemudian memutuskan untuk menyerahkan diri kepada tentara Jepang. Sedgemen dan dua orang awa kapal kemudian mencoba berunding dengan beberapa tentara Jepang setelah menemukan kamp mereka.

Hal serupa juga dialami oleh dua kelompok lainnya. Mereka sudah bisa menebak apa yang akan terjadi tetapi tidak bisa berbuat apa-apa kecuali diam. Namun kali ini, para tentara Jepang memerintahkan mereka berjalan menuju pantai hingga masuk ke dalam air di kedalaman tertentu sebelum mulai menembaki para tawanan ini.

Ian W. Shaw (2010: 221), hal ini seperti mimpi bagi Vivian. Sejak menjadi seorang suster, ia telah menyaksikan perang yang mencekam di Malaya dan Singapura, tubuhnya hanyut menuju pantai dengan beberapa luka tembak. la kemudian memutuskan untuk menghilang ke hutan melalui jalur yang pernah ia lewati sebelumnya bersama Bill Sedgeman. la berjalan kira-kira sejauh 20 kilometer ke dalam hutan hingga kelelahan dan roboh. la meninggalkan jalur tersebut dan berjalan beberapa meter ke dalam hutan hingga tiba di semak belukar dan terdapat sebuah liang disana, didalam sebuah gua kecil yang gelap. la memutuskan untuk beristirahat disana.

Setelah merasa cukup baik dan bahan makanannya mulai menipis ia memustuskan untuk pergi ke arah pantai dan ia juga melewati beberapa pondok nelayan, ketiak ia mendekati sebuah pondok, ia mendengar sebuah suara memanggilnya dan ia menemukan seorang tawanan yang selamat dari penembakan di pantai Radji, seperti yang di tuturkan oleh lan W Shaw berikut:

Kingsley terluka di bagian tangan kanan dengan luka diseluruh otot tangannya, ia juga terlukan di bagian bahu. Vivian memeriksa luka Kingsley dan dengan cepat berkata bahwa Kingsley beruntung masih hidup. Luka di lengannya sangat parah, dan juga terdapat dua luka lain di telapak tangannya. Kingsley sangat lemak untuk berjalan, jadi Vivian membopongnya berjalan menuju hutan dan menemukan liang lain yang lebih besar untuk mereka berdua. la kemudian kembali lagi ke Pantai Radji untuk mengambil beberapa peralatan medis dan beberapa botol air minum sebelum kembali lagi ke liang tersebut.

Jumat, tanggal 20 Februari, Vivian berjalan beberapa kilometer menuju sebuah kampung, ia mejelaskan keadaannya dan Kingsley pada seorang lelaki tua yang sebelumnya berbicara dengan Sedgeman. la kemudian meninggalkan kampung dengan membawa beberapa bahan makanan yang dibungkus dengan daun pisang. Sayuran, nasi, dan sedikit daging dicampur dalam bungkusan tadi. la dan Kingsley bertahan selama dua hari dengan makanan tersebut.

Setelah beberapa kali menerima bahan makanan dari kapung tersebut, pada jari rabu tanggal 25 Februari ketika ia 
datang ke kampung seorang wanita mengatakan kepadanya bahwa itu adalah makanan terakhir yang dapat ia berikan, karena ia takut ketahuan tentara Jepang. la juga mengatakan bahwa ada beberapa oarng yang memakai pakaian yang sama seperti Vivian dibawa ke Kamp di mentok oleh tentara Jepang.

Vivian kembali ke tempat Kingsley menunggu dan mulai berdiskusi. Mereka akbirnya memutuskan untuk menyerahkan diri kepada tentara Jepang pada tanggal 28 Februari dan ditawan di kamp milik Jepang selama tiga tahun hingga Jepang menyerah tanpa syarat kepada sekutu ketika kalah di Perang dunia II pada bulan Agustus 1945. Namun, Private Kingsley meninggal ketika masih menjadi tawanan karena mengalami infeksi akibat luka tembakan bayonet di tangannya.

\section{Gambaran Kehidupan di Pulau Bangka melalui Kesaksian Vivian Bullwinkle}

Muntok adalah ibukota kabupaten Bangka Barat provinsi Kepulauan Bangka Belitung dengan luas wilayah 1.090.468 $\mathrm{km}^{2}$. Kota Muntok terletak di bagian paling barat pulau Bangka dan merupakan akses terdekat dari Sumatera Selatan menuju Bangka atau sebaliknya. Letak kota Muntok secara geografis yaitu, disebelah utara berbatasan dengan Laut Natuna dan kecamatan Jebus, disebelah timur berbatasan dengan Kecamatan Simpang Teritip, disebelah selatan berbatasan dengan selat Bangka, dan disebelah barat berbatasan dengan Laut Natuna dan Selat Bangka. Kondisi masyarakat Muntok secara garis besar terdiri dari tiga suku yaitu: orang Melayu, orang Cina, dan orang Arab. Bahasa Melayu adalah bahasa yang digunakan dalam kehidupan sehari-hari.

Kota Muntok merupakan salah satu kota yang menyimpang banyak sejarah. Muntok telah menjadi perhatian sejak masa Sriwijaya, pemerintah Hindia Belanda, masa Penjajahan jepang, hingga ketika Masa kebangkitan Nasional. Hingga sekarang masih banyak bangunan-bangunan bersejarah yang masih berdiri dan terawat di kota Muntok.

Muntok juga pernah mengalami masa krisis ketika masa penjajahan Jepang terhitung sejak tahun 1942-1945. Dai Nippon mendarat di Bangka pada tanggal 14 Februari 1942. Pesawat Dai Nippon yang hanya sekali-sekali melintas di atas kota Muntok, makin lama makin sering, bahkan sampai enam kali dalam satu hari. Meskipun pesawat-pesawat tersebut selalu melintas diatas kota Muntok, tapi penyerangannya hanya dilakukan sebanyak tiga kali. Sewaktu Nippon sudah menduduki Bangka pun, pertempuran udara masih sering terjadi dan dapat disaksiakn oleh rakyat yang mendiami wilayah pantai. Kedatangan Jepang menyisakan kenangan sedih dan tragis pada sebagian besar rakyat (Tim Penyusun, 2012:23).

Dari penjelasan diatas dapat disimpulkan bahwa kondisi masyarakat Muntok pada zaman penjajahan Jepang sangat memprihatinkan. Banyak orang meninggal karena kekurangan gizi atau terserang penyakit malaria. Masyarakat harus patuh dan menjalani tradisi bulanan Jepang serta melakukan kerja paksa. Banyak penambang Cina yang bekerja ditambang timah memutuskan untuk pergi dari lokasi tambang dan mulai membuka ladang di hutan sehingga mereka dapat menghindari kerja paksa. Jepang memiliki banyak tawanan perang di Muntok sehingga sebagian dari tawanan perang tersebut harus dipindahkan ke Palembang. Kondisi sosial ekonomi masyarakat menurun drastis, produksi timah juga menurun karena kurangnya suku cadang mesinmesin tambang.

\section{Kehidupan Vivian Bullwinkle selama Menjadi Tawanan Perang Jepang}

Setelah menyerahkan diri kepada tentara Jepang pada tanggal 28 Februari, Vivian dan Kingsley dibawa ke kamp Jepang di Muntok. Ketika mereka tiba, 
seorang tentara mulai menanyai mereka beberapa pertanyaan. Mereka menceritakan bahwa kapal mereka di tenggelamkan minggu lalu, ketika mencapai daratan mereka mulai berjalan menelusuri hutan. Bahan makanan mereka peroleh dengan menemukan buah hutan, meminta bantuan di kampung ataupun mencuri beberapa makanan dari kampung.

Pembunuhan massal yang terjadi di pantai Radji dikenang di beberapa tempat dengan dibangunnya monumen yang terdapat di Muntok dan juga di Australia. Australian War Memorial dalam guide to a paper for Vivian Bullwinkle dan dalam journal of the Australian war memorial oleh Hank Nelson juga memberikan keterangan mengenai pembunuhan massal tersebut seperti yang dituturkan dibawah ini:

Ketika tiba di kamp tawanan perang, ia bertemu dengan rekan-rekannya sesama juru rawat Australia, juru rawat senior dari 2/10 AGH Nesta James, kemudian juru rawat senior dari 2/13 AGH Jean Ashton serta beberapa rekan lainnya. Mereka semua berkumpul di sebuah pondok dan Vivian mulai menceritakan peristiwa yang terjadi selama seminggu terakhir. Rekanrekannya medengarkan sambil meneteskan air mata atas peristiwa mengerikan yang telah terjadi. Mereka menyadari bahwa Vivian Bullwinnke adalah saksi kunci dari pembunuhan massal tersebut dan ia harus dilindungi. Kejadian ini tidak boleh dibicarakan kembali dan mereka harus bungkam selama masih menjadi tawanan perang Jepang.

Berdasarkan catatan Jean Ashton, Vivian Bullwinkle tiba di kamp pada tanggal 28 Februari 1942 sehingga menambah jumlah juru rawat yang selamat menjadi 32 orang dan sekitar 2000 orang telah menjadi tawanan perang. Ketika ia tiba di kamp keadaan kamp sangat sesak, 40-45 orang ditempatkan dalam setiap ruangan dan terdengar suara tangisan anak-anak kecil. Vivian Bullwinkle juga menceritakan keadaan kamp buruh milik Jepang yang ia dan teman-temannya tinggali selama berada di Muntok. lan W. Shaw mengatakan dalam bukunya yang berjudul On Radji Beach sebagai berikut:

Kamp tersebut berbentuk letter $U$ dengan beberapa ruangan. bagia paling depan adalah pos penjaga tentara Jepang. kemudian dibelakang pos penjaga terdapat sebuah beranda. Pada bagian kanan kamp terdapat tiga ruangan yang digunakan sebagai bangsal rumah sakit dan disebelahnya terdapat tiga ruangan yang digunakan sebagai kamp para pria. Sedangkan berhadapan dengan rumah sakit dan kamp pria terdapat enam ruangan yang dihuni oleh para tawanan wanita dan anakanak. Pada bagian tengah kamp terdapat sebuah bangsal dan pada bagian belakang adalah dapur umum. Toilet umum terletak di belakang ruangan para wanita dan anakanak.

Keadaan kamp Jepang di Muntok sangat memprihatinkan. Mereka harus tinggal dalam ruangan yang kecil dengan ruang untuk masing-masing orang hanya selebar tubuh mereka. Dalam catatan Jean Ashton dijelaskan bahwa ketika ia tiba di kamp buruh milik Jepang di Muntok keadaan ruangan mereka sangat kotor dengan bau yang tidak sedap dari kamar mandi yang terletak berdekatan dengan ruangan mereka. Keadaan akan bertambah buruk saat malam tiba karena ruangan mereka akan dipenuhi banyak nyamuk sehingga menyebabkan mereka tidak dapat tidur.

Para tawanan harus mengantri dalam antrian yang panjang untuk mendapat jatah makan di halaman kamp. Makanan tersebut hanya terdiri dari semangkuk nasi, terkadang juga disediakan the atau kopi yang terlalu encer. Mereka akan mendapat makanan dua kali dalam sehari pada pukul 11.00 dan pada pukul 17.00. para tawanan semakin bertambah karena Jepang membom lebih banyak kapal yang berangkat dari Singapura sejak tanggal 1316 Februari 1942. 
Pada akhir minggu pertam setelah tinggal di kamp tawanan Jepang di Muntok Vivia mendapat sebuah pesan dari seorang dokter yang mengatakan bahwa ada seorang tentara Inggris bernama Pat Kingsley ingin bertemu dengannya. Ketika tiba di bangsal rumah sakit, dokter yang menangani Kingsley mengatakan bahwa ia memiliki sebuah lubang peluru di paruparunya dan paru-parnya sudah terinfeksi berat. Jika dirawat di rumah sakit modern, Kingsley akan mendapatkan pengobatan yang maksimal sehingga dapat menyembuhkan infeksinya. Namun keadaan disini sangat berbeda dan rumah sakit ini hanya memiliki pengobatan seadanya yang tidak mampu menghentikan infeksi pada paru-paru Kingsley. Ketika Vivian tiba Kingsley dalam keadaan koma dan nyawanya tidak tertolong lagi.

Setelah satu minggu tinggal di kamp buruh milik Jepang di kawasan Muntok terhitung sejak pengeboman Vyner Brooke, pada tanggal 2 Maret 1942 para juru rawat Australia tersebut di pindahkan ke kamp yang baru melintasi selat Bangka yaitu ke Palembang, Sumatera. Mereka tiba di Palembang sekitar pukul 5 sore keesokan harinya. Keadaan kamp di Palembang ini ternyata lebih baik dibandingkan dengan keadaan kamp di Muntok. Ruangan yang tersedia cukup besar dan bersih. Mereka disediakan nasi dan beberapa potong biskuit untuk sarapan pagi dan pada tengah hari akan disediakan nasi dengan sayur mayur. Pada tanggal 4 April 1942 rombongan lain dari Muntok tiba dan mereka hanya terdiri dari para wanita serta anak-anak. Keadaan mereka sangat memprihatinkan, beberapa dari mereka menderita malaria dan disentri.

Ketika menjadi tawanan perang di Palembang mereka tinggal di kawasan Bukit Besar. Suster Vivian Bullwikle pernah mengirimkan sebuah surat kepada ibunya Eva Bullwinkle yang isinya memberitahukan bahwa ia telah menjadi tawanan perang
Jepang di Pulau Bangka dan Sumatera saat itu.

Mereka memiliki seorang komando yang disebut Miachi dalam kamp tawanan Perang. Didalam adat-istiadat Jepang terdapat hukum Bushido dengan 8 butir prinsip. Miachi samasekali tidak dapat menerapkan prinsip Bushido selama menjabat sebagai komando dalam kamp tawanan perang, berikut alasannya:

Dengan demikian, dari enam puluh lima orang juru rawat hanya dua puluh empat orang termasuk suster Vivian Bullwinkle yang dapat pulang ke Australia setelah Perang Dunia II usai. Suster Vivian Bullwibkle kemudian memberikan kesaksiannya di pengadilan Tokyo atas kekejaman Jepang dan tragedi Vyner Brooke yang dialami beliau bersama rekanrekannya. Pada tanggal 2 Maret 1993 suster Vivian Bullwinkle bersama keluarga para juru rawat yang selamat dari kamp tawanan Jepang kembali ke Muntok untuk meresmikan sebuah monumen atas nama pemerintahan Australia (Tim Penyusun, 2012:24). Begitu pula dalam data yang di muat di Australian War Memorial berikut:

Keterangan yang dikemukakan oleh suster Vivian Bullwinkle telah memberikan penjelasan lebih mendalam mengenai kronologi tragedi penembakan terhadap HMS Vyner Brooke serta pembunuhan massal yang dilakukan tentara Jepang di kawasan Pantai Radji. Suster Vivian Bullwinkle juga menceritakan hari-harinya selama menjadi tawanan perang Jepang selama tiga setengah tahun. Kesaksian beliau mengungkap satu sisi penjajahan Jepang lainnya selain pada tujuan utama Jepang yang memobilisasi bangsa Indonesia untuk ikut serta di Perang Asia Pasifik.

\section{SIMPULAN}

Berdasarkan hasil penelitian dan pembahasan dapat disimpulkan bahwa kesaksian Vivian Bullwinkle sebagai korban kekejaman Jepang di Pulau Bangka pada tahun 1942 dapat dijadikan sebagai sumber 
pembelajaran karena kesaksian Vivian Bullwinkle pemerintahan Jepang di Indonesia pada awal dan akhir pemerintahannya serta kehidupan militer pada zaman penjajahan Jepang. Kesaksian Vivian Bullwinkle memberikan gambaran lebih detail mengenai kehidupan masyarakat selama Penjajahan Jepang. Selain itu kesaksian Vivian Bullwinkle juga berdampak baik bagi kota Muntok karena melalui kesaksian beliau maka kota Muntok dapat di kenal di PBB.

\section{DAFTAR PUSTAKA}

Abdurrahman, Dudung. 1999. Metode Penelitian Sejarah. Jakarta: Logos Wacana IImu.

Agung S, Leo. 2012. Sejarah Asia timur I. Yogyakarta: Ombak.

Aman. 2011. Model Evaluasi Pembelajaran Sejarah. Yogyakarta: Ombak.

Angell, Barbara. 2003. A Woman's War: The Exceptional Life of Wilma Oram Young, AM. Australia: New Holland Publishers.

Arif, Muhamad. 2011. Pengantar Kajian Sejarah. Jakarta: Yrama Widya

Arikunto, Suharsimi. 2013. Penelitian Suatu Pendekatan Praktek. Jakarta: Rineka Cipta

Ashton, Jean. 1987. Jean's Diary: A POW Diary 1942-9945. Australia: Jill Ashton.

Bull, Victoria (ed). 2015. Oxford Learner's Pocket Dictionary: Fourth Edition. United Kingdom: Oxford University Press.

Daliman. A. 2012. Metode Penelitian Sejarah. Yogyakarta: Ombak.

Darling, Pat. 2013. Portrait of A Nurse: Prisoner of War of Japanese 19421945 Sumatera. Australia: Don Wall.

Dimyati dan Mudjiono. 2013. Belajar dan Pembelajaran. Jakarta: Rineka Cipta.
Erman, Erwiza. 2009. Menguak Sejarah Timah Bangka-Belitung. Yogyakarta: Ombak.

Hamalik, Oemar. 2013. Kurikulum dan Pembelajaran. Jakarta: Bumi Aksara.

Hamdani. 2011. Strategi belajar Mengajar. Bandung: CV Pustakaan Setia.

Ricklefs. M.C. 2011. Sejarah Indonesia Modern. Yogyakarta: Gadjah Mada University Press.

Gottschalk, Louis. 1985. Mengerti Sejarah. Jakarta: Universitas Indonesia.

Sanjaya, Wina. 2007. Strategi Pembelajaran: Berorientasi Standar Proses Pendidikan. Jakarta: Kencana

Shaw. lan. W. 2010. On Radji Beach. Australia. Pan Macmillan.

Siregar, Eviline dan Hartini Nara.2014. Teori Belajar dan Pembelajaran. Bogor: Galia Indonesia.

Sutopo, H.B. 2006. Metodologi: Dasar Teori dan Terapannya dalam Penelitian. Surakarta: Universitas Sebelas Maret.

Tamburaka, Rustam E. 2002. Pengantar IImu Sejarah: Teori Filsafat Sejarah, Sejarah Filsafat \& Iptek. Jakarta: Rineka Cipta.

Theo, Rika dan Fennie Lie. 2014. Kisah, kultur, dan Tradisi Tionghoa Bangka. Jakarta: Kompas Media Nusantara.

Tim Penyusun. 2012. Sejarah Kota Muntok. Bangka Barat: Dinas Perhubungan, Pariwisata, Kebudayaan, dan Informatika.

Tim Penyusun. 2015. Pedoman Penulisan Skripsi. Palembang: Universitas PGRI Palembang.

Ulung, Gagas. 2010. Amazing Bangka Belitung. Jakarta: PT Gramedia Pustaka Utama.

Usman, Husaini dan Purnomo Setiady Akbar. 2014. Metodologi Penelitian Sosial. Jakarta: Bumi Aksara. 
